\title{
Traceability technology: fruits and vegetables trader case study
}

\author{
Arsenii Shevchuk \\ Rotterdam University of Applied \\ Sciences \\ Master of Logistics Management \\ Rotterdam, Netherlands \\ arseniishevchuknl@gmail.com
}

\begin{abstract}
The food industry is centralized around one major element - the consumer. The changing expectations of consumers drive the industry. The dominating advantage of purchase triggers such as price, taste and convenience during the past years started losing positions to such factors as health, safety and experience. These drivers of the consumer value equation are based on the overarching factor - transparency. In the case of the agri-food sector - the consumer is not able to access transparent information about the product if end-to-end traceability across the supply chain is not available. Based on the case study example, it was defined that there is a need for technology that can bridge information flow in the chain and can potentially ensure traceability for end consumers. The pineapple supply chain was chosen as an example for this study in order to narrow down the scope. This study was based on a qualitative approach, with the usage of such data gathering techniques like desk research and semi-structured interviews. For the analysis of the data, such methods like content and narrow analysis were used. The result of the analysis showed that blockchain technology could be seen as a perspective tool for the traceability in the pineapple supply chain. Furtherly, based on the analysis of the internal processes in combination with outcomes of the technology expert interviews and desk research - the technology integration concept was defined. It was concluded that even though blockchain can be seen as an effective solution for food chain traceability, there is still a need of the market research that should prove the hypothesis regarding the need to the traceability in the food industry.
\end{abstract}

Keywords - Food supply chain, Traceability, Blockchain, Identification, Technology integration.

\section{INTRODUCTION}

According to the report presented by the Deloitte [1], 51\% of the consumers are willing to pay more for healthy and safe food, and this percentage continues to grow [1]. Consumers demand the traceability that can be verified as an essential aspect of safety and quality. In order to fulfil this demand, the need for the system that can provide information about the origin and life-cycle of the goods arise [2]. In the case of the agri-food sector - the consumer is not able to access transparent information about the product if end-to-end traceability across the supply chain is not available [2]. The management of the company expects that customers will request a service that can enable consumers to trace information about the particular product from the "farm to fork" in a reliable and trustable manner. However, the problem is that currently, the company is not able to provide this kind of service due to reasons such as lack of alignment between the data systems of the supply chain members, lack of the information standardization and inability to fully identify and authenticate the traceable product. Therefore, the company lacks the knowledge about technology that could potentially bridge these gaps, be up-to-date and be used as a traceability platform in its supply chain. Taking into consideration these challenges, the main research question for this study was formulated as follows - "Which technology should be chosen and how can it be integrated into the pineapple supply chain of the company in order to ensure traceability?".

\section{MethodOLOGY}

This research was based on the qualitative approach as it focuses on a case study of a single company. Qualitative techniques are covered both - collection and analysis stages of the research project. In this particular case, such data collections methods of qualitative research like - desk research and semi-structured interviews were used. The usage of these techniques helped to receive an in-depth understanding of the current situation and practices in the pineapple supply chain and also about the defined technology concept. Firstly data was gathered by using such collection methods like desk research and interviews. Secondly, data were analyzed by using techniques like narrative and content analysis. Thirdly, based on the findings the conclusion was drawn and recommendations to the company were provided. For this research, the purposive homogeneous technique was used. Homogeneous sampling focuses on one subgroup in which sample members are similar, such as a particular occupation or expertise area [3]. Experts were identified based on the following criteria's. They should have experience with the defined traceability technology in supply chain management (preferably food sector). The sample size was established based on the information from Saunders [3]. In his book, he mentioned that in the case when a semi-structured interview is used, the sample size should include from 5 to 25 participants [3]. Based on that, it was determined that this study should have at least 5 participants for this part of data gathering. In order to find the experts, the social network, LinkedIn was used. The requests for the interview were sent to the 52 experts; from this number 33 did not respond. So 19 potential participants showed interest. However, due to the different reasons, it was possible to conduct an interview with 8 of them, which is already higher than the minimal level for this type of research. 
TABLE 1. EXTERNAL EXPERTS THAT PARTICIPATED IN THE INTERVIEWS.

\begin{tabular}{|c|c|}
\hline Respondent & Organization \\
\hline Respondent 1 & IBM \\
\hline Respondent 2 & DataFastlane \\
\hline Respondent 3 & Exertis: Supply chain services \\
\hline Respondent 4 & Ripe.IO \\
\hline Respondent 5 & The Fork \\
\hline Respondent 6 & The Fork \\
\hline Respondent 7 & Capgemini \\
\hline Respondent 8 & UNISOT \\
\hline
\end{tabular}

\section{RESULTS}

\section{A. Literature study}

\section{Food supply chain}

The food supply chain can be seen as a network of interconnected stakeholders working together to make goods available, rather than a singular chain. In simple words - the food supply chain is a series of operations, procedures and entities that help to bring food from the raw material to the plate of consumers [4]. Agri-food supply chain management is comprised of the set of unique characteristics, that distinguish it from a typical supply chain. List of the characteristics includes: Unique nature of the products, due to the perishability of goods and limited life-cycle; Variability of quantity and quality on-farm inputs; Specifications for transportation, storage, quality conditions and safety; Need of complying with regulations and food safety procedures and also a need of specialized attributes like traceability and visibility [5].

\section{Traceability}

Traceability can be defined in different ways depending on the observed industry. According to the Espiñeira \& Santaclara [6] in the case of the food supply chains traceability can be defined as follows - "The ability to identify at any specified stage of the food chain (from production to distribution) from where the food came (one step back) and to where the food went (one step forward) [6]. The increasing demand for sustainable food pushes companies to implement traceability systems along the food supply chains. However, the implementation of such systems has become difficult due to such aspects like usage of the conventional systems, undeveloped information systems in the supply chain which prevents real-time tracking and end-to-end visibility [7]. One of the core factors that should be considered in the traceability system is standardization. Standardization allows achieving rapid, correct, efficient and protected information exchange process between the supply chain participants. The creation of information standards can accomplish this alignment. The information standards should include agreements on the format used, content and meaning of the data that will be shared between the supply chain participants and the communication tool or method that will be used for processing it [6]. According to the Verdouw [8], the following list contains the most valuable supply chain information standards: Identification standards (codes) - digital number plates related to the particular products, items and locations. Codes are used as access keys for the application through the entire chain, like usage of RFID and tracking and tracing.
Auto-ID standards: mutual agreements regarding the physical size of the barcodes or RFID chips. Data communication standards: technical agreement about how related data should be distributed between participants. (by the usage of the internet). Standard messages: mutual agreements on the structure of the shared messages, regarding the content and relevance [8].

\section{Technology affordances and constraints}

Theory of Constraints was developed by Eli Goldratt in early 1980's. Theory of Constraints claims that management of the organization should focus on the few aspects, which prevents the achieving of the goal [9]. The model of the Eli Goldbratt was upgraded by Floyd and Ronen (1992) as a result two additional steps were introduced: Set-up the system's goal and Determine the performance measures. So the combined system was consist of the following steps:

1. Set-up the system's goal

2. Determine the performance measures

3. Identify the system's bottlenecks

4. Decide How to Exploit the Constraint

5. Subordinate everything else to the above decision.

6. Elevate the system's bottlenecks

7. If, in a previous step, a bottleneck has been broken go back to step 3 [10] [11].

The concept of technology affordance means what individual or organization can achieve by the usage of the particular information system when technology constraints refer to barriers that could prevent achieving of the goals while using the information system. [12].

\section{ICT}

Majority of companies are implementing the information technologies in the operations in order to streamline SCM activities [13] Information technologies that are used for supply chain management purposes could be divided into three major categories: Transaction processing (improvement of the information flow efficiency), supply chain planning and collaboration (sharing of the information related to planning and scheduling) and order tracking and delivery coordination (monitoring of individual shipments and orders). Each category can help to process information and as a result, use it in the various parts of the particular business model [14].

\section{Current trends}

In a recent report (2019) presented by the World Economic Forum and McKinsey, the food supply chain experts and consultants outline a so called "Transformative twelve" - list of the technologies that in the upcoming ten years will create an impact on the food systems. From this list, experts outline three core technologies that will support the innovation in traceability systems. These technologies are "Food sensing technologies", "Internet of Things" and "Blockchain" [15]. The "Food sensing technologies" and "Internet of Things" are based on the sensor technology platform, which means they are suitable for the real-time tracking, automated data capturing and identification of the elements through the supply chain. In the same time, Blockchain is based on the distributed ledger technology. Distributed ledger enables 
more accessible gathering, analysis, integration and distribution of the data. Both sensor and distributed ledger technologies in combination with data elements and unique identifiers creating the traceability system.

\section{B. Empirical study}

\section{Technology concept}

In order to identify traceability technology for the organization, three technologies mentioned in the current trends chapter - IoT, blockchain and Food sensing technologies were taken into consideration. The secondary desk research was done in order to investigate the chosen solutions. The findings from the desk research were allocated to the comparison table. The table illustrated the name, description, benefits and uncertainties and the possible alternatives of the particular technology. Findings represented in the table were used during the interview with ICT manager of the company in order to identify a technology concept model. Based on the outcomes of the interview, it was defined that blockchain is the most preferable solution, based on it is characteristics and applications. According to Jude (2016), the high level of interest about the blockchain technology strives companies to start a digital transformation in order to solve business-related issues (Umeh, 2016). Therefore, many IT managers from different fields try to apply it in almost any project, which is not entirely correct. Managers should be able to identify the reasons to use blockchain clearly, especially from a data management perspective (Casino, Dasaklis, \& Patsakis, 2019). In his work Lo (2017) suggests that before the adoption of the blockchain, the management should examine the suitability of the blockchain, based on the use cases requirements (Sin Kuang \& Qinghua, 2017). In order to do that, the author introduced a suitability evaluation framework (Figure 1).

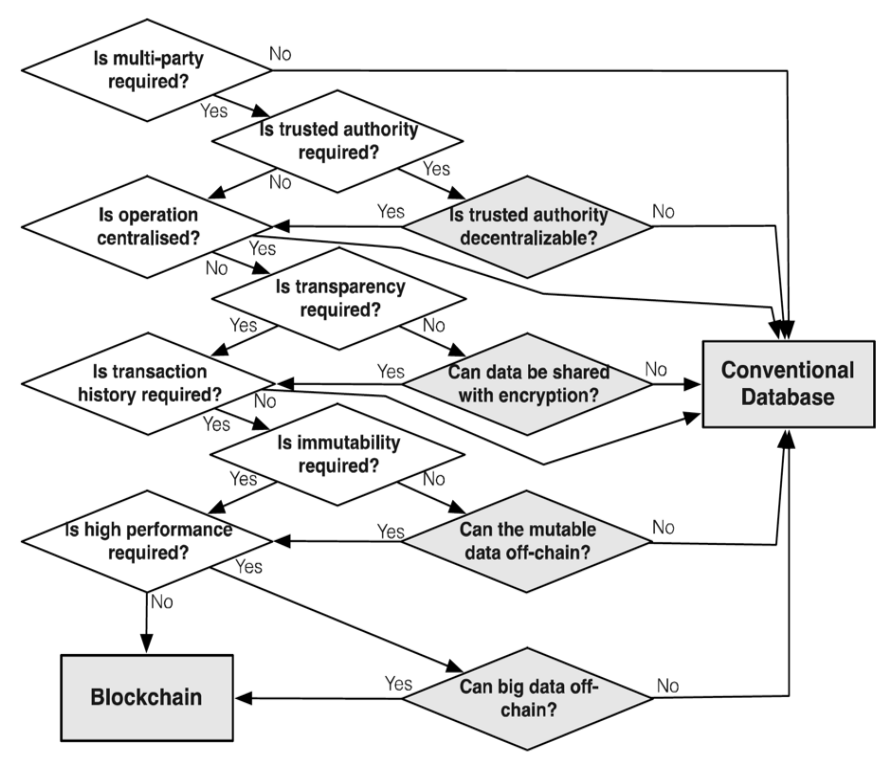

Fig. 1 Suitability Evaluation Framework

Company case was evaluated according to the questions represented in the framework. Based on the findings from the table, it can be concluded that blockchain can be seen as a better solution than conventional databases.
Table 2 illustrates the outcomes of the experts' interviews. It can be seen that all eight experts stated that blockchain could be seen as a solution for a food supply chain traceability, and they are not visible alternatives exist. Based on these findings, blockchain was defined as a technology concept for this case study and investigated furtherly.

TABLE 2. EXPERT INTERVIEW: OPINION ABOUT THE BLOCKCHAIN AS TRACEABILITY TECHNOLOGY FOR FOOD SUPPLY CHAINS

\begin{tabular}{|c|c|c|}
\hline Respondent & $\begin{array}{c}\text { See blockchain as a } \\
\text { solution? }\end{array}$ & $\begin{array}{c}\text { See better } \\
\text { alternatives? }\end{array}$ \\
\hline 1 & Yes & No \\
\hline 2 & Yes & No \\
\hline 3 & Partly & $\begin{array}{c}\text { Cheaper } \\
\text { systems }\end{array}$ \\
\hline 4 & Yes & No \\
\hline 5 & Yes & No \\
\hline 6 & Yes & $\begin{array}{c}\text { Cheaper } \\
\text { systems }\end{array}$ \\
\hline 7 & Yes & No \\
\hline 8 & Yes & No \\
\hline
\end{tabular}

\section{Technology integration concept}

In order to develop the integration concept of the blockchain as traceability technology in the pineapple supply chain, the series of empirical questions were answered. Thus, the integration concept for company is based on the combination of the findings.

\section{What is the technological background of the blockchain and what configuration of it is fit for company?}

Blockchain can be defined as the secure record of the transactions, which are collected into blocks and chained in chronological order and distributed between the different servers in order to create reliable provenance of the data, each block is interconnected with the next one using a cryptographic signature [16]. Blockchains allows having a distributed peer-to-peer network, where members that not trust each other can interact with each other and exclude the need of the trusted authority [17]. In their report, the Food and Agriculture Organization (2019) provides the following description of the blockchain types. In the private blockchain, only users with the specific permission could become a part of the network, and thus they can add and verify records to the blockchain. Public blockchains are decentralized, and everyone can join and leave the network; all information is visible to the public, and each network participants can initiate a transaction [18]. Table 3 represents the analysis of the blockchain types based on the interviews with the experts. It can be seen that there is no central tendency regarding the suggested blockchain type. Each of the blockchain types has benefits and drawbacks. Due to this fact, the particular conclusion about what type of blockchain should be considered by organization can be hardly made. However, experts underpinned their choices with various arguments illustrated in Table 4. Therefore management of the company could use them in order to make a decision. 
TABLE 3. EXPERT INTERVIEW: SUGGESTED BLOCKCHAIN TYPES

\begin{tabular}{|l|l|}
\hline Respondent & Advised Blockchain type \\
\hline 1 & Private \\
\hline 2 & Private \\
\hline 3 & Public/Private \\
\hline 4 & Private \\
\hline 5 & Public \\
\hline 6 & Public/Private \\
\hline 7 & Public/Private \\
\hline 8 & Public \\
\hline
\end{tabular}

TABLE 4. EXPERT INTERVIEW: BENEFITS AND SUITABILITY OF THE PUBLIC AND PRIVATE TYPE

\begin{tabular}{|l|l|}
\hline \multicolumn{1}{|c|}{ Public } & \multicolumn{1}{|c|}{ Private } \\
\hline - Brand image improvement & - Safety of the information \\
- More reliable & - Avoid of Proof-of-Work complexity \\
- Can be properly controlled despite the & - Avoid unknown partners \\
arguments of private solution supporters & - Bring efficiency to business processes \\
- Closer to initial idea of the technology & - Easier to implement \\
- Suitable for long-term projects & - Suitable for project with time limits \\
structures & \\
\hline
\end{tabular}

What are the current processes of the material and information flow in pineapple supply chain and which of them can be seen as constraints for integration of blockchain?

Traceability system should be able to differentiate both downstream and upstream flow in the supply chain, in other words, transformations of bulk product into the packaged good for the end user [19]. Thus, it was important to understand the processes in the pineapple supply chain. In order to to do this two models were used. The first model is the Product Flow Model or PFM. PFM can help to visualize the fundamental transformations to supply chain members and related product flow starting from the input material and toward the end product. [7]. And second model is Business Process Diagram or BPM. BPM helped to link by link describe the existing procedures and links between entities involved in the supply chain and illustrate a product life cycle mechanism [20]. The BPD and PFD diagrams provided indepth analysis of the current processes in the pineapples supply chain including information sharing procedures, the involvement of the different stakeholders and transformations of the product that is happening during the journey through the value chain of the company. Additionally, based on the Technology affordances and constraints theory, the processes or events that can be seen as constraints for the technology integration were outlined such as - lack of information standardization, pineapple labelling process and lack of knowledge and awareness of stakeholders. The lack of information standardization was outlined as one of the points that from the point of view of the company could prevent the achievement of end-to-end traceability. Thus, this question was discussed in the interviews. Table 5 illustrates the summary of findings. It can be seen that opinion or the experts is divided. Three respondents think that lack of information standardization it is not a problem and five state it as a problem. However, it should be pointed out that those respondents who provided a negative answer, underpin their point of view by the availability of the solutions that can bring standardization.

TABLE 5. EXPERT INTERVIEW: LACK OF THE INFORMATION STANDARDIZATION AND BLOCKCHAIN COMPATIBILITY

\begin{tabular}{|c|c|l|}
\hline Respondent & $\begin{array}{c}\text { Is it a } \\
\text { problem? }\end{array}$ & \multicolumn{1}{|c|}{ How it to solve it or why it is not a problem? } \\
\hline 1 & No & $\begin{array}{l}\text { Because the most of the traceability information usually already in } \\
\text { place. The digitalization of paper based not necessarily needed }\end{array}$ \\
\hline 2 & No & $\begin{array}{l}\text { Because blockchain is a technology and need standardization. Mainly } \\
\text { all known blockchain applications for traceability use GS1 EPCIS } \\
\text { standard. }\end{array}$ \\
\hline 3 & Yes & Create data standardization agreements between the members. \\
\hline 4 & Yes & $\begin{array}{l}\text { Designed internal application that is interoperable between the } \\
\text { application and blockchain layer }\end{array}$ \\
\hline 5 & Yes & $\begin{array}{l}\text { Designed of system similar to invoice scanning, that can automatically } \\
\text { proceed paper documents to the electronic format }\end{array}$ \\
\hline 6 & No & $\begin{array}{l}\text { Because blockchain can store various versions of the electronic formats } \\
\text { and paper based documents can be uploaded like a photo copy. }\end{array}$ \\
\hline 7 & Yes & Create data standardization agreements between the members \\
\hline 8 & Yes & Internal solution "Digital Twins" \\
\hline
\end{tabular}

How to align blockchain technology with the data systems of pineapple supply chain?

During preliminary research for this study was defined that currently, there is no alignment between the data systems of the supply chain participants. Table 6 illustrates an overview of the findings derived from the interviews with the external experts. Eight respondents were asked - "How can Blockchain be integrated with the data systems like ERP or EDI of the supply chain members?". Thus, $t$ was defined that internal databases could be connected to the blockchain via API or by developing of the web-portal in the case if one of the parties has an insufficient level of the ICT infrastructure.

TABLE 6. EXPERT INTERVIEW: WAY OF CONNECTION BETWEEN BLOCKCHAIN AND CURRENT DATA SYSTEMS

\begin{tabular}{|c|c|}
\hline Respondent & Solution summary \\
\hline 1 & $\begin{array}{l}\text { Use plug-in tools that can be connected via } \\
\text { API to the existing data systems; } \\
\text { Based on the solution IBM Food Trust }\end{array}$ \\
\hline 2 & $\begin{array}{l}\text { Consider creation of the application } \\
\text { platform (Cloud based) } \\
\text { Use API to connect to the existing data } \\
\text { systems; }\end{array}$ \\
\hline 3 & $\begin{array}{l}\text { Two solutions - API connection and web- } \\
\text { portal; }\end{array}$ \\
\hline 4 & $\begin{array}{l}\text { Two solutions - API connection and SDK } \\
\text { connection; }\end{array}$ \\
\hline 5 & $\begin{array}{l}\text { Use API to connect to the existing data } \\
\text { systems; }\end{array}$ \\
\hline 6 & - \\
\hline 7 & $\begin{array}{l}\text { Use API to connect to the existing } \\
\text { systems; }\end{array}$ \\
\hline 8 & $\begin{array}{l}\text { Use plug-in tools that can be connected via } \\
\text { API to the existing data systems; }\end{array}$ \\
\hline
\end{tabular}

In his report Banerjee (2018) outlining the importance of the integration of the blockchain with such systems like ERP, WMS, CRM and others. As all beforementioned systems are aimed to build, track, purchase and ship products, the integration of the blockchain will provide a copy of related to this information in an immutable form. So the combination of the systems will bring transparency of the movement and 
origin of goods that will be available at any point of time, for any purpose [21]

How to identify and authenticate information about the particular pineapple and connect it with technology?

Due to the perishable nature of the goods and complexity of the processes in the pineapple supply chain, the need to identify and authenticate product related information arise. [19]. Table 7 is divided into two columns. The first part illustrates their opinion regarding how to identify information about particular pineapple and the second part about how to authenticate information. It could be seen that almost all of the respondents outline QR codes as a solution for product identification. However, experts stated that there are no solid solution that can authenticate information.

TABLE 7. EXPERT INTERVIEW: SOLUTION FOR THE AUTHENTICATION AND VERIFICATION

\begin{tabular}{|l|l|l|}
\hline Respondent & $\begin{array}{c}\text { How to identify } \\
\text { information? }\end{array}$ & $\begin{array}{c}\text { How to authenticate } \\
\text { information? }\end{array}$ \\
\hline 1 & RFID, QR code & No solid solution \\
\hline 2 & QR code, bar-code & No solid solution \\
\hline 3 & QR code, RFID, IoT & No solid solution \\
\hline 4 & QR code & Tailored made solution \\
\hline 5 & QR code, bar-code & No solid solution \\
\hline 6 & QR code & - \\
\hline 7 & RFID & No solid solution \\
\hline 8 & QR code, bar-code & Tailored made solution \\
\hline
\end{tabular}

Table 8 illustrates opinion of the respondents regarding the way how to provide access to the information for the consumers. Half of the respondents mentioned that consumers can access information via a smartphone application and half supported the idea about the developing of the web-interface. It should be mentioned that all of the respondents outline the importance of QR code usage. Because scanning of QR code can provide access to directly to the blockchain itself or to the "mirror" repository.

TABLE 8. EXPERT INTERVIEW: ACCESS TO INFORMATION FOR CONSUMER

\begin{tabular}{|c|c|}
\hline Respondent & $\begin{array}{c}\text { How to provide access to the information } \\
\text { for consumer? }\end{array}$ \\
\hline 1 & Via web-interface \\
\hline 2 & Via smartphone application \\
\hline 3 & Via smartphone application \\
\hline 4 & Via web-interface \\
\hline 5 & Via smartphone application \\
\hline 6 & Via web-interface \\
\hline 7 & Via web-interface \\
\hline 8 & Via smartphone application \\
\hline
\end{tabular}

Which factors should be considered by company before the technology integration?

The second part of the main research question is intended to provide a recommendation to about how the defined technology can be integrated. Thus, it is essential to outline aspects that should be considered by company before the integration of the blockchain. In order to do this, the following questions were discussed during the interviews with the experts. First, they were asked if it is possible to use blockchain as a standalone technology and which support technologies could be implemented. Secondly, they were asked to identify essential preparation steps for the integration. As a third question, the cost and time for integration were discussed. The last question was focused on the implementation accomplishment. Figure 2 shows the summary of the findings derived from the expert interviews. It should be also mentioned that experts stated that integration of the blockchain should be outsourced, mainly due to the complexity of the process.

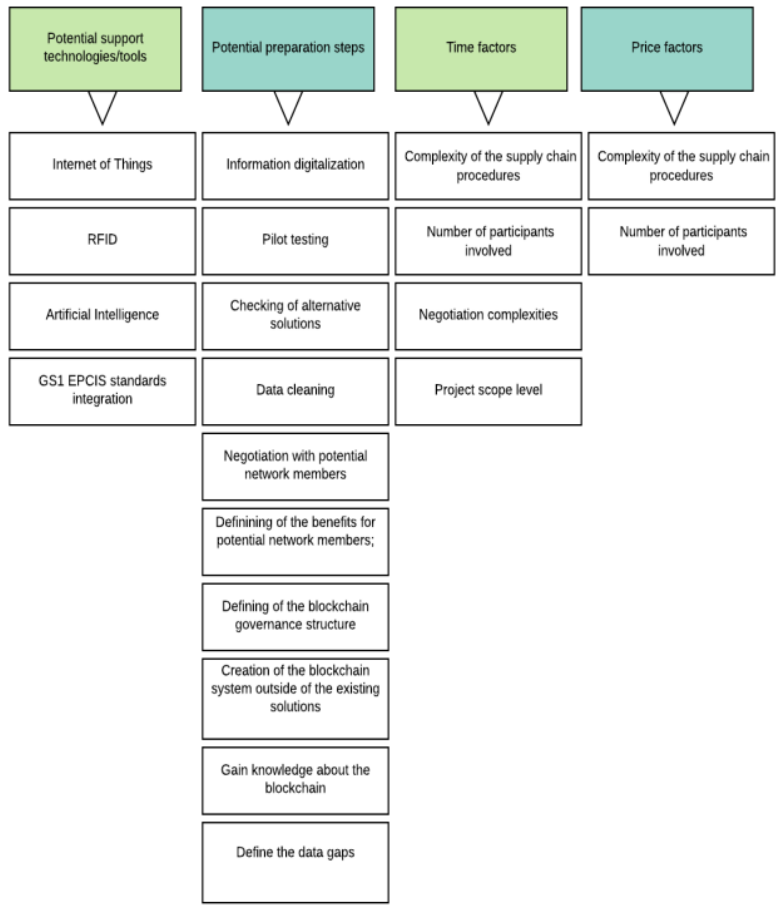

Fig. 2 Considerations factors summary chart

\section{DISCUSSION}

Despite the increasing number of research papers about the blockchain technology and it is applications, the number of studies which are focused on the actual integration of it is limited. A more significant part of this study was aimed to develop an integration concept based on the particular business case of the food trader. Therefore part of the findings that were discussed in an initial study not included in this article in respect to privacy reasons. However, due to the fact that food supply chains have similar models and processes, part of the findings could be potentially applied for other companies which operate in the food sector, especially as a trader. Quite possible that other food traders could face similar issues like - difficulties with the choice of the blockchain type to be applied or lack of information flow standardization. While also face issues based such as lack of interconnection between the data systems and difficulties with identification and authentication of the product-related information. Additionally, consideration factors that were outlined in this article can be applied to any food business that is planning to use blockchain as a traceability platform, in order to prepare the company for the integration of technology. Thus, 
blockchain can be seen as a potential technology that can enable end-to-end traceability in the supply chain, and it can be integrated despite the several constraints. Since there is a possibility to integrate the blockchain into the pineapple supply chain, it will be useful to define what kind of information should be stored in it. Information can be distinguished into two categories: internal, for value members of the supply chain and external, that might be available for the consumers. In order to identify the type of information that needs to be gathered, in-depth cross assessment of stakeholders' needs should be conducted. In order to define external information, it might be useful to create a survey that can be shared among consumers of the customer. In this way, in-depth insights about the real state of the consumer demand towards transparency can be defined. Moreover, based on the findings, it might be easier to build a plan for a real proof-ofconcept project.

\section{CONCLUSION}

"Current trends" chapter, three technologies were defined to support innovation in food traceability systems. Defined technologies were analyzed based on their characteristics and allocated to the comparison table. Then this table was shared with the ICT manager and discussed during the interview in order to identify technology which potentially meets the requirements of the company. As a result of the interview, blockchain technology was outlined. After that, additional desk research was done. Findings of the desk research showed that blockchain technology is a better solution than conventional databases based on the supply chain cases. Additionally, the applicability of the blockchain as traceability technology was discussed during the interview with the external experts. Most of the experts confirmed that blockchain is a potential solution, especially in the food supply chain management. The integration concept of the blockchain as traceability technology in the pineapple supply chain was based on findings derived from several questions. Based on the outcomes of interviews, it was defined that each of the blockchain types has benefits and drawbacks. Since the opinions of the experts were divided in an almost similar way, the certain conclusion about what type of blockchain should be considered by the organization was not made. The BPD and PFD were made. Based on these diagrams, the informationsharing procedures, the involvement of different stakeholders and product transformations were mapped. After, TACT theory was applied where the processes such as Information standardization, pineapple labelling, and lack of knowledge and awareness of the stakeholders were identified as constraints for technology integration. It was defined that internal databases could be connected to the blockchain via API or by developing a web-portal. Moreover, the findings from the desk research indicated that if the connection between the blockchain and internal databases is achieved, it can potentially bring more transparency to the supply chain activities. Based on the findings from the interviews, it was defined that pineapples could be traced by the integration of QR codes or RFID tags to them. While for the authentication problem, a particular solution was not defined, since no reliable solution currently exists. Moreover, it was defined that in order to provide access to traceable information, either an application or web-interface should be developed. Based on the findings from the interviews, the four categories of the factors were developed: Potential support technologies, potential preparation steps, time factors and cost factors. Each category consists of the sub-steps which were described in details. Despite this, before starting the preparation of the proof-of-concept projects it will be important to investigate what information should be stored in the blockchain. By accessing both internal supply chain participants and final consumers. This research will help to prove the hypothesis that demands on sustainable food are growing and as a result prove that there is a need for technology that can ensure endto-end traceability

\section{REFERENCES}

[1] Deloitte Consulting LLP, "Capitalizing on the shifting consumer food value equation," Deloitte Development LLC, 2016

[2] M. A. a. S. Chang, "Traceability in a food supply chain: Safety and quality perspectives," Food Control, pp. 172-184, 2014.

[3] M. Saunders, Research Methonds for Business students, Harlow: Pearson Education Limited, 2016.

[4] S. Dani, Food Supply Chain management and Logistics, London: Kogan Page Limited, 2015.

[5] E. Iakovou and D. Bochtis, Supply Chain Management for Sustainable Food Networks, Chichester: John Wiley \& Sons, Ltd, 2016.

[6] M. Espiñeira and F. Santaclara, Advances in Food Traceability Techniques and Technologies: Improving Quality Throughout the Food Chain, Cambridge: Elsevier, 2016

[7] H. Scholten, C. Verdouw, A. Beulens and J. van der Vorst, "Defining and Analyzing Traceability Systems in Food Supply Chains," in Advances in Food Traceability Techniques and Technologies , Cambridge, Elsevier, 2016, pp. 9-10.

[8] C. Verdouw, "Towards a smarter greenport: public-private partnership to boost digital standardisation and innovation in the Dutch horticulture," International Journal on Food System Dynamics, pp. 44-52, 2014.

[9] G. Nitza and N. Ahituv, "A Theory of Constraints approach to Interorganizational systems implementation," Information Systems and eBusiness Management, pp. 341-360, 2008.

[10] E. M. Goldratt, THE GOAL A Process of Ongoing Improvement THIRD REVISED EDITION, The North River Press Publishing Corporation, 2004.

[11]B. Ronen and Y. Spector, "Managing systems constraints: a cost/utilization approach," International Journal of Production Research, pp. 2045-2061, 1992.

[12] Majchrzak and M. Lynne Markus, "TECHNOLOGY AFFORDANCES AND CONSTRAINTS THEORY (OF MIS)," in Encyclopedia of Management Theory, New-York, SAGE Publications, Inc., 2013, pp. 832-835.

[13] G. Li, H. Yang and L. Sun, "The impact of IT implementation on supply chain integration and performance," Int. J.ProductionEconomics, pp. 125-138, 2009.

[14] J. Auramo, "The roles of information technology in supply chain management," Helsinki University of Technology journal, pp. 4-7, 2014.

[15] World Economic Forum; McKinsey \& Company, "Innovation with a Purpose: Improving Traceability in Food Value Chains through Technology Innovations," World Economic Forum, Geneva, 2019.

[16] J. Angelis and R. d. Silva, "Blockchain adoption: A value driver perspective," Business Horizons, pp. 307-314, 2019.

[17] K. Christidis and M. Devetsikiotis, "Blockchains and Smart Contracts for the Internet of Things," IEEE Access , pp. 2292 - 2303, 2016.

[18]FAO, "E-agriculture in action: Blockchain for agriculture. Opportunities and challenges," ood and Agriculture Organization of the United Nations (FAO) and International Telecommunication Union (ITU), Bangok, 2019

[19] J. Trienekens, "Transparency in complex dynamic food supply chains," Advanced Engineering Informatics, pp. 55-65, 2012.

[20]GS1, "Business process and system requirements for full chain traceability," 2009. [Online]. Available: http://www.gs1.org/docs/ gsmp/traceability/GS1_Global_Traceability_Standard_i1.pdf.

[21] Banerjee, "INTEGRATING BLOCKCHAIN WITH ERP FOR A TRANSPARENT SUPPLY CHAIN," Infosys Limited, Bengaluru, 2018. 
[22]P. Verschuren and H. Dooreward, Designing a Research Project, The Hague: Eleven International Publishing, 2010.

[23] D. Cooper and P. Schindler, BUSINESS RESEARCH METHODS, New York: McGraw-Hill/Irwin, 2014 